\title{
CAISSON WALL BREAKAGE OF SLOPING TOP BREAKWATER DUE TO COLLISION OF LARGE WAVE DISSIPATING BLOCKS
}

\author{
Kojiro Suzuki, Port and Airport Research Institute (PARI), suzuki k@pari.go.jp \\ Kenichiro Shimosako, PARI, shimosako@pari.go.jp \\ Ryota Gushi, Okinawa General Bureau, Cabinet Office, gushi710@ogb.cao.go.jp
}

\section{INTRODUCTION}

A sloping top breakwater covered with wave dissipating blocks (STBWB) has been developed and placed in service under extremely large wave conditions in Japan. The U-breakwater in N-port, designed as an STBWB, and constructed using 50t Dolos (Kd number 20) has been in service since the 1980s. Recently, newly developed 100t wave dissipating blocks (Kd number 10) were used to extend the U-breakwater. The stability of the new U-breakwater blocks was certificated by hydraulic experiment of detailed design. However, breakage of caisson wall, as shown in Figure 1, was caused by the large wave energy of Typhoon 19 in 2014. To clarify the failure mechanics, we conducted a series of hydraulic experiments.

\section{EXPERIMENT}

The experiments were performed using a flume with a main-flume length of $105 \mathrm{~m}$ and a width of $0.8 \mathrm{~m}$. The experiment were conducted on a 1/25-scale according to Froude model law. We used irregular waves whose wave height $H_{1 / 3}$ and wave period $T_{1 / 3}$ were set as $H_{1 / 3}=0.43 \mathrm{~m}$ (10.8m in prototype scale) and $T_{1 / 3}=2.9 \mathrm{~s}(14.5 \mathrm{~s}$ in prototype scale). In the front wall of caisson model, we installed load cells, wave pressure gauges and acceleration sensors to measure the collision force of wave dissipating blocks.

\section{CONCLUSIONS}

Through the experiment, the following were clarified.

1) Wave dissipating blocks of the STBWB are unstable compared with the conventional vertical breakwater covered with wave dissipating blocks (CBWB) because most of the STBWB blocks are submerged and are easily affected by buoyancy during wave action, as shown in Figure 3.

2) Upper wave dissipating blocks of the STBWB easily tremble and collide with the top of the caisson front wall. In contrast, the upper wave dissipating blocks of the CBWB collide with the massive concrete cap installed on the caisson.

3) Figure 4 shows the time series of the collision force. The maximum collision force was $224.6 \mathrm{~N}$ (3.51MN in prototype scale). This was 1.5 times larger than the punching shear load-carrying capacity of the RC caisson wall.

4) The relative damage, $N_{0}$, of the STBWB was 0.18 and less than the design value, 0.3 . Even though the relative damage, $N_{0}$, and displacement of the wave dissipating blocks are small, the wave dissipating blocks collide with the caisson wall because of its trembling. Because the wave dissipating blocks of the U-breakwater were large, $100 \mathrm{t}$, even trembling of the blocks caused a large collision force.

\section{REFERENCES}

Sato, Yamagata, Takahashi, Furukawa and Hosoyamada (1992): Hydraulic Characteristics of Sloping Top Breakwater Covered with Wave Dissipating Blocks, Proc. Japanese Conf. of Coastal Eng., Vol.39, pp.556-560.

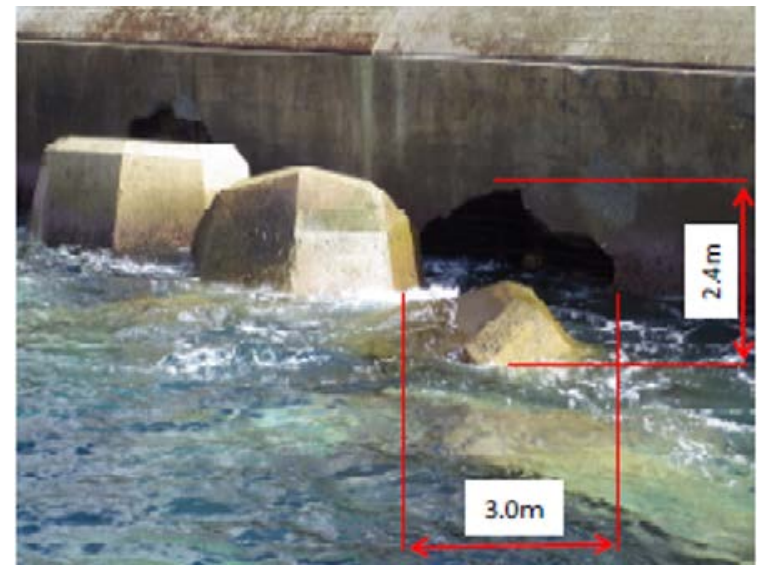

Figure 1 - Caisson Wall Breakage of the U-Breakwater due to Collision of the Wave Dissipating Blocks

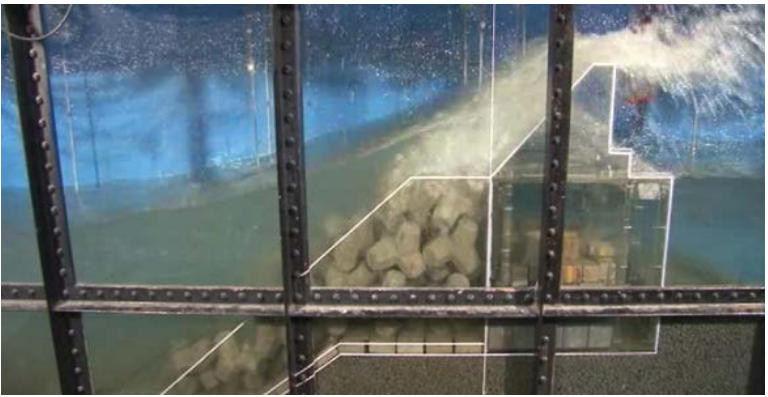

Figure 2 - Hydraulic Experiment of the U-Breakwater

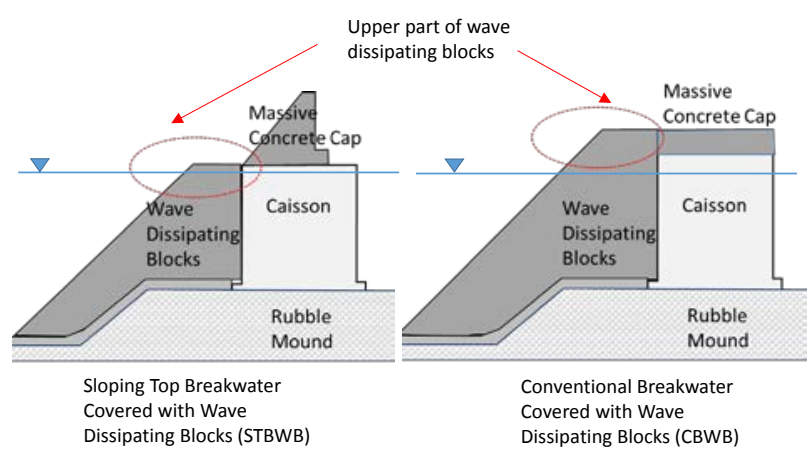

Figure 3 - Comparison between STBWB and CBWB

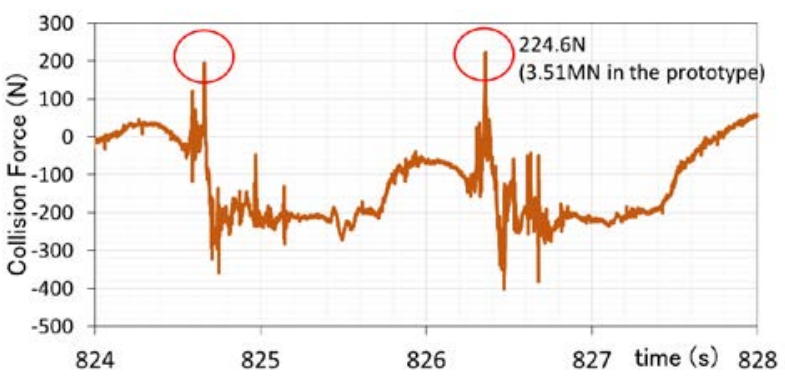

Figure 4 - Time Series of the Collision Force 